
\title{
25 Research Soure \\ Lipid Emulsion And Isoflurane: The Quality Assessment of Anesthesia Parameters In Pigeons
}

\author{
Alireza Ghazanfariasl \\ faculty of veterinary medicine, Semnan University \\ Ebrahim Shahroozian ( $\nabla$ shahroozian@semnan.ac.ir) \\ Semnan University https://orcid.org/0000-0001-9723-7028 \\ Keyvan Keramati \\ Semnan University \\ Hamidreza Moslemi \\ Semnan University
}

\section{Research Article}

Keywords: pigeon, lipid emulsions, isoflurane, emulsified isoflurane, anesthesia

Posted Date: September 20th, 2021

DOI: https://doi.org/10.21203/rs.3.rs-876740/v1

License: (c) (1) This work is licensed under a Creative Commons Attribution 4.0 International License. Read Full License 


\section{Abstract}

An objective was to evaluate the efficacy of intravenous (IV) emulsified isoflurane formulation for maintenance of general anesthesia and to compare with IV lipid emulsion infusion with inhalation isoflurane in pigeons. The animals was total of 21 healthy, mature pigeons (Columba livia domestica), weighing $318 \pm 13 \mathrm{~g}$. Pigeons were anesthetized by emulsified isoflurane (treatment III), inhalation isoflurane with IV lipid emulsion (treatment II ), and inhalation isoflurane (treatment I) alone. Over 50 minutes, wing tone, toe pinch (pedal), and feather pluck reflex were tested every 10 minutes. Data was recorded at 10, 20 and 30 minutes for temperature $(T)$, peripheral hemoglobin oxygen saturation $\left(\mathrm{SpO}_{2}\right)$ heart rate $(H R)$, and respiratory rate $\left(f_{R}\right)$. A scoring system was used to assess parameters related to anesthesia duration and depth. There were no significant differences in hemodynamic variables between the treatment I and treatments II and III, in treatments associated with fat emulsion have shown faster induction, longer anesthesia, more immobilization, and longer recovery time. Furthermore, in anesthesia depth percentages evaluation it was observed that emulsified isoflurane entered the anesthesia deep stage earlier and was removed immediately after discontinuation of administration.

Administration of $8 \% \mathrm{v} / \mathrm{v}$ emulsified isoflurane IV was effective in anesthesia rapid induction, stability in depth of anesthesia, rapid withdrawal from anesthesia depth by discontinuation of the infusion, delayed recovery, cardiorespiratory and $(\mathrm{T})$ stability.

\section{Introduction}

The anatomical and physiological characteristics of birds are different from mammals. Part of the daily works of veterinary clinics and hospitals in the poultry medicine field is to restrain avians either manually or by analgesic or anesthetic method. The manual method in birds especially sick ones, causes an increase in body $(T),\left(f_{R}\right)$ and $(H R)$ and increases blood corticosterone levels and induces stress. Hence, for ethical reasons, the use of anesthetics and sedatives enhances behaviorally and psychologically the bird's ability to tolerate any stressful condition such as surgical interventions, pain relief, radiographs, ophthalmic examinations, minor physical examinations, diagnostic purposes and sampling. Therefore, the use of these drugs and their application and management is important in birds (Lee \& Lennox., 2016; Lierz \& Korbel, 2012).

Isoflurane is widely used as an anesthetic agent for both human and animal patients because of its chemical and physical characteristics, such as low blood-gas partition coefficient and lack of cardiac arrhythmia effects. In avian patients, inhalation administration of Isoflurane and Sevoflurane is a choice method at veterinary clinics. However, hypothermia especially in smaller avian, is the main risk of inhalation administration. Due to head mask typical usage in inhalation anesthesia in birds, high amount of waste gas, difficulty in surgical procedures especially on head structures and spontaneously breathing stoppage are the other disadvantages of inhalation anesthesia (Lierz \& Korbel, 2012; Natalini et al., 2017, 2016). 
Also, in some cases such as field situations, lack of accessibility to inhalation anesthesia equipment, injectable anesthesia is an alternative choice. The difficulty in dosage adjustment after anesthesia drug administration within a surgical process, challenges in measuring the right weight of avian patients, short surgical procedures, cardiopulmonary depression and hazardous anesthesia in patients with kidney and liver failure are the main disadvantages of injectable anesthesia (Lierz \& Korbel, 2012).

As an alternative to inhalation anesthesia, emulsified halogenated agents in IV form are growing interest. However, IV administration of halogenated anesthetic agent alone can cause adverse effects, but numerous studies have shown that emulsified halogenated anesthetics which administrated IV have synergistic effects on protecting organs, such as brain, heart, and kidneys and can prevent their side effects. It has also been shown maximum protection against cardiac ischemia reperfusion, strong antiinflammatory and antiapoptotic effects (Natalini et al., 2017, 2016; Zhou et al., 2006).

IV administration of halogenated anesthetics should have some advantages over the inhalation method, such as less atmospheric unnecessary exposure, ease of administration, and elimination of specialized delivery equipment, such as source of oxygen and a vaporizer (Yang et al., 2006).

IV lipid emulsion (ILE) has been used for more than five decades as a part of parenteral nutrition source in hospitalized patients. Recently, in addition to nutritional therapeutic roles, the roles of non-nutritional therapeutic have been introduced for these compounds as a common practice in human medicine and much less in veterinary medicine. Despite unclear mechanisms of lipid emulsion action, the examples of these roles can be including lipid rescue and drug carrier vehicle (Buysa et al., 2015).

Several commercial compounds based on plant (soybean or olive) and fish resources have been identified and used around the world. There are currently four generations of lipid emulsions, the most common of which is Intralipid® ${ }^{\circledR}$ with 10, 20 and 30\% concentration. There is a concentration limit of 3.5-8 $\%$ v/v when halogenated anesthesia emulsified with lipid (Parrish, 2017; Zhou et al., 2006)

Many studies in rats, dogs, mice and swine have been shown that kinetic properties of IV emulsified halogenated anesthetic are different from inhaled isoflurane. Due to anesthesia circuit circumvention and the independent functional residual capacity of lungs, induction of anesthesia with IV emulsified halogenated anesthetics is more rapid. Reducing the volume of the central compartment and the total volume of distribution, minimize the equilibration between blood, brain, and other tissue. The lungs are the main organs for elimination of IV emulsified halogenated anesthetics and it can be used in patients with liver and kidney failures. Also, IV emulsified halogenated anesthetics anesthesia recovery is rapid and smooth (Natalini et al., 2017, 2016; Zhou et al., 2006)

Since no study has examined the effects of the IV emulsified isoflurane on birds in anesthesia and IV lipid emulsion effects in anesthesia with inhaled isoflurane on birds, so the purpose of this study was to evaluate the effects of IV administration of emulsified isoflurane $8 \%$ on the anesthesia time parameters, quality, and the safety of general anesthesia in pigeons as a new approach in bird's general anesthesia. Also, we compared IV emulsified isoflurane with, simultaneous administration of inhaled isoflurane and 
IV lipid emulsion in quality of anesthesia. The hypothesis was that the time of induction and recovery would be more rapid with IV emulsified Isoflurane than inhaled Isoflurane. We also hypothesized by constant infusion of emulsified isoflurane, surgical anesthesia will be observed with more stability in heodynamical variables.

\section{Materials And Methods}

\section{Animal care}

The experimental procedures were performed in compliance with the Ethics Committee of Laboratory Animals, Faculty of Veterinary Medicine, Semnan University (NO. 1397/27/3-64).

\section{Preparation of $8 \% \mathrm{v} / \mathrm{v}$ emulsified isoflurane}

Isoflrane (AErrane ${ }^{\mathrm{TM}}$, Baxter Healthcare Corp., USA) and Intralipid ${ }^{\circledR} 30 \%$ (Fresenius Kabi Austria GmbH) was obtained from Semnan Kowsar Hospital. Lipid-emulsified isoflurane prepared as previously described by others. In order to prepare the combination of $8 \% \mathrm{v} / \mathrm{v}, 0.4 \mathrm{ml}$ of liquid isoflurane with $4.6 \mathrm{ml}$ of Intralipid ${ }^{\circledR}$, lipid was injected into sealed sterile vial. A maximum concentration of $8 \%$ can be used in emulsified isoflurane formulations. (Natalini et al., 2017; Zhou et al., 2006). The maximum amount of fluid that can be given continuously with a syringe pump is $20 \mathrm{~mL} \mathrm{~kg}^{-1}$ hour-1.(Bowles et al., 2007) Vials were placed in an orbital shaker at $1.43 \mathrm{~g}$ for 10 minutes (KJ-201BD ${ }^{\mathrm{TM}}$, Jiangsu Kangjian Medical Apparatus Co., Ltd). Due to the lack of information about the stability and sterility, the vials were prepared on the day of study.

\section{Study preparation}

A Total of twenty-one (11 male and 10 female) pigeons (Columba Livia domestica), clinically healthy and mature weighing mean \pm standard deviation (SD) $318 \pm 30 \mathrm{~g}$ and 6 to 12 months old were taken from birds shelter of Semnan, Iran. Ten days before starting the study, pigeons were allowed to adapt to their housing. They were housed in a quiet room with a temperature of mean \pm standard deviation (SD) $23 \pm 3 C^{\circ}$ and cage sizes were approximately $1 * 0.5 * 1.5 \mathrm{~m}$ made of drainage wooden floor with stainless steel frames and shelf-like perching. To prevent any stress during this study, which could cause metabolic changes, pigeons were fed with a wheat-based diet. Following previous feeding regimen water was available libitum. The pigeons of each sex were randomly assigned to three treatments. Three hours before starting the study, they were deprived of being fed.

\section{Animal instrumentation}

By using an aseptic technique, a 26 gauge polyethylene catheter (Vitromed Healthcare, India) was inserted into medial metatarsal vein. After catheterization, pigeons were intubated (Rusch ${ }^{\circledR} 2 \mathrm{~mm}$ plain endotracheal tube). Before instrumentation, to avoid any other drugs intervention during the study, pigeons were intranasally sedated by $0 / 2-0 / 3 \mathrm{ml}$ of isoflurane through intranasal droplets. After 
intubation, pigeons were placed in dorsal recumbency and two electrodes of patient monitoring were placed at propatagium (basal wing) and two other electrodes were placed at lateral head of gastrocnemius muscle. Pulse oximetry $\left(\mathrm{SpO}_{2}\right)$ probe was placed on the other foot of pigeons.

All pigeons during the study were connected to vaporizer (Narkomed $2 \mathrm{~A}^{\mathrm{TM}}$, Draeger Medical Inc) using a Bain nonrebreathing delivery system by an endotracheal tube. The IV injections were administrated by a syringe pump (SP-500 TM , JMS Co.,Ltd). All vital signs, including $(H R),\left(f_{R}\right),(T)$ and $\left(\mathrm{SpO}_{2}\right)$ were checked out during anesthesia by vital signs monitoring system (URIT-A63A ${ }^{\mathrm{TM}}$, Hasvet Medical Co. $L t d$,$) . Vaporizer was set to 4 \%$ isoflurane and $1\left(L_{\text { minute }}{ }^{-1}\right)$ oxygen flow rate and $3 \%$ isoflurane and $0 / 5\left(\mathrm{~L} \mathrm{minute}^{-1}\right)$ oxygen flow rate, respectively for induction and maintenance.

\section{Study design}

In the first treatment, pigeons were anesthetized by inhalational isoflurane and IV normal saline (n: 7; 3 males and 4 females: treatment I ( $\left.\left(S_{\mathrm{I}}-\mathrm{SAL}_{\mathrm{IV}}\right)\right)$. In the second treatment, pigeons were anesthetized by inhalational isoflurane and IV Intralipid ${ }^{\circledR}$ (n: 7; 4 males and 3 females: treatment II (ISO,-LIPIV)). In the third treatment, pigeons were anesthetized by IV emulsified isoflurane 8\% (n: 7; 4 males and 3 females: treatment III $\left.\left(\mathrm{LIP}-\mathrm{ISO}_{\mathrm{IV}}-\mathrm{O}_{2 \mathrm{I}}\right)\right)$. All treatments administered IV by syringe pump with infusion rate of 20 $\mathrm{mL} \mathrm{kg}^{-1}$ hour ${ }^{-1}$.

\section{Anesthesia monitoring}

To assess the anesthesia stages, time-related parameters of anesthesia, several reflex stimulants, and Hemodynamical variables were evaluated and calculated. These reflex stimulants included palpebral, corneal, cere, pupillary, wing tone, cloaca, toe pinch (pedal), and feather pluck. To assess toe pinch reflex, pigeon toe slightly pinched by using an atraumatic forceps ( $\mathrm{Nopa}^{\mathrm{TM}}$ instruments Medizintechnik $\mathrm{GmbH}$, Germany). To prevent the variety of responses to stimulants, all reflexes were assessed by the same person.(Lierz \& Korbel, 2012).

The reflex stimulation was assessed on each individual pigeon every 10 minutes after administration of an anesthetic agent. The numerical scale-based method was used for depth assessment and condition of anesthesia. Number 0 means that a reflex reaction to stimulation was observed while number 1 means that no reflex reaction was observed. The number of each reflex was recorded separately and the different anesthetic stages and time-related parameters were expressed as the sum of numbers at 10 minutes intervals for each pigeon. The percentage between 0 and 20 was considered as the stage I. The stage II ranged from 20 to 60 and stage III was from 60 to 100 . Stage III was equally divided into three parts; I (light), II (medium) and III (deep) which ranged from 60-73, 74-87 and 88-100 respectively. These scales and calculation methods detailed according to the descriptions of clinical anesthetic depth assessment in birds, mice and rabbits and Guedel's classification (Figure 1). (Kawai et al., 2011; Silva et al., 2011; Lierz \& Korbel, 2012) 
Head Dropping Time (HD): The time (minutes) between anesthesia agent administration and head dropping

Head Lifting Time ( $\mathrm{HL})$ : The time (minutes) between anesthesia agent withdrawal and head lifting Immobilization time (ImT): The time interval (minutes) between dropping and lifting the head Induction time (InT): The time interval (minutes) between head dropping and stage III Duration of anesthesia (DA): The time (minutes) duration that birds were in stage III Emergence time (ET): The time interval (minutes) between stage III and lifting the head

\section{Statistical analysis}

All data were analyzed statistically by SPSS version 21 . Normal distribution was tested with one-sample Kolmogorov-Smirnov. Parametric data were analyzed by using One-Way ANOVA and followed by Tukey post hoc test with a $p$-value of $<0.05$ and nonparametric data were analyzed by Mann-Whitney test. Time trend data were analyzed with repeated measure test $(p<0.05)$.(Figure 2$)$

\section{Results}

\section{General considerations}

The mean weight of pigeons, stabilization time, volume of intranasal isoflurane droplets and room's temperature, statistically didn't have any significant differences between treatments. (Table 1)

\section{Time-related parameters}

\section{Treatment I (ISO,-SAL $)$}

Induction time in this treatment was more than others, also immobilization time, anesthesia duration and recovery time was lesser than other treatments.

\section{Treatment II (ISO,-LIP IV)}

Immobilization time and also recovery time was more than other treatments but induction time was more than treatment III.

\section{Treatment III (LIP-ISO $\left.\mathrm{IV}-\mathrm{O}_{21}\right)$}

Due to the least induction time, anesthesia duration in treatment III was more than other treatments.

\section{Stages of anesthesia}


Different stages of anesthesia were determined by ordering a score and reported as a percentage. Based on calculated percentages and Guedel's classification, treatment III entered to stage III (stage of surgical anesthesia) earlier than the other treatments. All treatments were in stage III at 20 minutes;and at 30 minutes all treatments emerged from stage III of anesthesia. Based on the graph gradient, treatment III emerged faster than the others and entered to stage I (stage of analgesia) earlier. treatment I at 10 minutes after administration was in part I of surgical anesthesia and both II and III treatments and were in part II and part III of surgical anesthesia respectively. Statistical analysis showed significant differences between treatment I and treatments II and III at 10 and 30 minutes (Figure 1).

A conceptual and creative idea was adopted in this study to understand better and compare different treatments. In these graphs, anesthesia stages and time-related parameter were combined together.

\section{(Figure 3)}

\section{Hemodynamic variables}

$(\mathrm{HR}),\left(\mathrm{f}_{\mathrm{R}}\right),\left(\mathrm{SpO}_{2}\right)$ and $(\mathrm{T})$ were recorded before and immediately after administration of anesthetic agents at 10 minute intervals. $(\mathrm{HR}),\left(\mathrm{f}_{\mathrm{R}}\right),\left(\mathrm{SpO}_{2}\right)$ and $(\mathrm{T})$ did not express any significant statistical differences among treatments during the study.

\section{Discussion}

The obtained data of our study focused on qualitative aspects. The results of our study in evaluation of anesthesia parameters in treatments, which associated with fat emulsion have shown faster induction, longer anesthesia, more immobilization and longer recovery time. Additionally, the survey of anesthesia depth percentages shown that emulsified isoflurane entered the anesthesia depth earlier and was removed immediately after discontinuation of administration and also, it remained longer time in deep (surgical) anesthesia during the infusion. There were no significant differences among treatments in hemodynamical variables following the administration of emulsified isoflurane, and stability in $(T)$ and situational indicators, was observed.

In a study that examined postconditioning of emulsified isoflurane against myocardial infarction, it showed rapid recovery for emulsified isoflurane in comparison with propofol, and expressed a remarkable hemodynamic stability. Furthermore, IV administration of emulsified isoflurane required significantly less isoflurane to obtain comparable anesthetic (Yan et al., 2012).

In another study that applied 15\% isoflurane lipid nanoemulsion IV for general anesthesia in dogs, the induction time of anesthesia was reduced and more stable and faster anesthesia was observed than inhalation exposure (Natalini et al,. 2017). 
In the emulsification of other volatile anesthetics, such as halothane and isoflurane in pigs and dogs respectively, faster induction, faster recovery and more stable dynamic status than the inhalation treatment were reported (Musser et al., 1999; Natalini et al., 2016).

The safe concentrations of anesthetic compounds and dose-response relationship of emulsified isoflurane in rats were also investigated. Compared to propofol, the time to return from anesthesia (forepaw righting reflex) was significantly shorter. It also created a faster recovery. It had a comparable safety index compared to propofol. Moreover, the administration of emulsified isoflurane required less isoflurane to reach anesthesia and the effects of organic protection that mentioned (Zhou et al., 2006).

The formulation of fat emulsion significantly affects the kinetics and dynamics of the drug. A two-part model, in the administration of bolus and fat emulsion infusions, has been seen in these compounds. Rapid induction can be due to the rapid release of isoflurane from the fat emulsion and rapid recovery can be due to the redistribution to the fat emulsion and its removal through the lungs. The depth of anesthesia changes with the speed of infusion. The fat emulsion reduces the volume of the central compartment ten times and reduces the total volume of distribution three times and also increases the safety of the drug compared with lipid-free compounds. These compounds have lower MAC than inhaled ones and create more desirable hemodynamic profile. No significant histopathological or Hemodynamical changes were observed. (Musser et al., 1999; Yang et al., 2013; Natalini et al., 2017).

A study by Yang et al., which examined the minimum alveolar concentrations of emulsified isoflurane and inhaled isoflurane in dogs expressed that, the primary route of elimination of emulsified isoflurane was through the lungs. In the inhalation method, for inducing and maintaining of anesthesia, the difference between the alveolar gases and the arterial blood should be a positive value while in the IV emulsified isoflurane method is a negative value. However, in order to maintain the anesthesia, the partial arterial pressure of isoflurane (indicating the partial pressure in central nervous system) must be the same between the IV and inhalation methods. It is also important to balance the isoflurane concentration between the alveoli and the arterial partial pressure, which is longer in the inhalation method, so it is expected to take a longer time for induction of anesthesia and more consumption than the IV method. The infusion of fat emulsion increases the blood/gas partition coefficient, indicating that isoflurane dissolves more easily in blood and it is difficult to remove from the blood into the lungs. Also, the minimum venous concentration and the minimum arterial concentration in IV group were higher than the inhalation group (Yang et al., 2006).

In a study, the effects of IV emulsified halogenated anesthetics were examined on acute and delayed preconditioning against myocardial infarction in rabbits. It was described that the lipid vehicles increased the amount of isoflurane in the myocardium; in other words, increase the release of active anesthetic in the site of action into the cardiac myocytes (Chiari et al., 2004).

The increase of tissue solubility and the decrease of drug availability about isoflurane pulmonary elimination may explain the differences between the alveolar concentration mean in the inhalation route and the IV route. It would also decrease the amounts of required anesthetics to produce general 
anesthesia. On the other hand, emulsified halogenated anesthetics may increase the solubility and uptake in body tissues and both raising the volume of its distribution and potency. This may concentrate the halogenated anesthetic in body tissues including the brain, and it can be potentially harmful to patients. Besides, the blood/gas partition coefficient of IV isoflurane with inhalation showed a significant increase. It can decrease the clearance of isoflurane and reduce the pulmonary excretion (Li et al., 2014; Natalini et al., 2017).

Lipid emulsion (LE) delayed the maximum effect and prolonged the duration of epinephrine efficacy on mean arterial pressure (MAP), but did not change the maximum increase in MAP or the heart rate response. This could be interference at the level of receptor binding. LE may delay the initial release due to sequestration of epinephrine into a lipid compartment or binding of epinephrine to its receptors and/or delay its dissociation (Carreiro et al., 2013).

After IV administration, the concentration of isoflurane in pulmonary blood and then in pulmonary alveoli increases, which may cause temporary hypoxia in the animals. In this study, $\mathrm{SpO}_{2}$ values were not significantly distinct in different groups. Hemodynamic and respiratory stability were also observed despite the use of painful stimuli. No significant changes were observed in heart rate and respiration between groups. There was adequate muscle relaxation in the study. Isoflurane has been reported to exert the potential effects on the center of thermotaxis and reduce the animal's temperature. To deal with this issue, appropriate pads were used during anesthesia in all treatments (Qin et al., 2014).

Jiang et al. evaluated the preanesthetic effects of ketamine-xylazine on hemodynamical changes in anesthetized pigs with emulsified isoflurane and showed that emulsified isoflurane could produce stable hemodynamic and temperature conditions. In another study on the pig model hemodynamic and respiratory stability was reported (Jiang et al., 2014).

Limitations of this study include non-calculation of volume consumption, dose optimization, measurement of blood concentration, the minimum alveolar concentration of isoflurane, and kinetic indices of composition. However, 14 days after the study, the pigeons were monitored for mortality, biochemical and hematological parameters for evaluation of safety were not measured.

\section{Conclusion}

This study showed that, emulsified isoflurane $8 \%$ can make the sufficient depth of anesthesia in pigeons. Rapid induction of anesthesia, stability in anesthesia depth during emulsified isoflurane infusion, rapid withdrawal from the depth of anesthesia by discontinuing of infusion, delayed recovery, cardiorespiratory and $(T)$ stability were the achievements of our study. Despite the interesting results shown in the scientific literature on the safety and efficacy and toxicity characteristics of this compound in laboratory animals, the use of emulsified halogens for IV injection requires the study of other aspects such as other laboratory animals on a larger scale, dosage optimization, and its side effects. 


\section{Declarations}

\section{Acknowledgements}

This article is presented as a partial requirement for the first author (Ghazanfariasl) to obtain a Doctor of veterinary medicine (DVM) degree at Semnan University, Faculty of veterinary medicine. The authors thank pharmacist Dr. Seyede Saghar Taheri for providing emulsion lipid and isoflurane.

\section{Funding}

This study was funded by the faculty of veterinary medicine, Semnan university.

\section{Conflicts of interest}

The authors declare that they have no conflict of interest.

\section{Availability of data and material}

The data that support the findings of this study are available as part of the article, and additional information is available on request from the corresponding author.

\section{Code availability}

Not applicable

\section{Authors' contributions}

All authors contributed to the study conception and design. Ghazanfariasl Alireza: Executor and preparation of manuscript. Shahroozian Ebrahim: data interpretation, statistical analysis, data management, and preparation of the manuscript. Keramati Keyvan: study design and data management. Moslemi Hamidreza: Advisor on conducting the study.

\section{Ethics approval}

All institutional guidelines for the care and use of pigeons were strictly followed. The experimental procedures were performed in compliance with the Ethics Committee of Laboratory Animals, Faculty of Veterinary Medicine, Semnan University (NO. 1397/27/3-64).

\section{Consent to participate}

All authors read and approved the final manuscript.

\section{Consent for publication}

All authors gave their consent for research publication. 


\section{References}

1. Bowles H, Lichtenberger M, Lennox A (2007) Emergency and Critical Care of Pet Birds. Vet Clin North Am Exot Anim Pract 10:345-394. https://doi.org/10.1016/j.cvex.2007.04.001

2. Buysa M, Scheepersa PA, Levina Al (2015) Lipid emulsion therapy: Non-nutritive uses of lipid emulsions in anaesthesia and intensive care. South African J Anaesth Analg 21:124-130. https://doi.org/10.1080/22201181.2015.1095470

3. Carreiro S, Blum J, Jay G et al (2013) Intravenous Lipid Emulsion Alters the Hemodynamic Response to Epinephrine in a Rat Model. J Med Toxicol 9:220 - 225. https://doi.org/10.1007/s13181-0130291-1

4. Cascorbi HF, Helrich M, Krantz JC et al (1968) Hazards of methoxyflurane emulsions in man. Anesth Analg 47:557-559. https://doi.org/10.1213/00000539-196809000-00019

5. Chiari PC, Bienengraeber MW, Weihrauch D et al (2005) Role of endothelial nitric oxide synthase as a trigger and mediator of isoflurane-induced delayed preconditioning in rabbit. Anesthesiology 103:74-83. https://doi.org/10.1097/00000542-200507000-00014

6. Huang H, Zhou C, Liu J et al (2016) Adding Emulsified Isoflurane to Cardioplegia Solution Produces Cardiac Protection in a Dog Cardiopulmonary Bypass Model. Nat Publ Gr 6:1-7. https://doi.org/10.1038/srep23572

7. Jiang S, Hu K, Fan HG et al (2014) Effects of ketamine / xylazine premedication on emulsified isoflurane general anaesthesia in swine undergoing embryo transplantation. Vet Med 59:325-330. https://doi.org/10.17221/7618-VETMED

8. Kawai S, Takagi Y, Kaneko S et al (2011) Effect of three types of mixed anesthetic agents alternate to ketamine in mice. Exp Anim 60:481-487. https://doi.org/10.1538/expanim.60.481

9. Lee A, Lennox A (2016) Sedation and Local Anesthesia as an Alternative to General Anesthesia in Three Birds. J Exot Pet Med 25:100-105. https://doi.org/10.1053/j.jepm.2016.03.012

10. Li Q, Yang D, Liu J et al (2014) Intravenous lipid emulsion improves recovery time and quality from isoflurane anaesthesia: A double-blind clinical trial. Basic Clin Pharmacol Toxicol 115:222-228. https://doi.org/10.1111/bcpt.12223

11. Lierz M, Korbel R (2012) Anesthesia and Analgesia in Birds. JEPM 21:44-58. https://doi.org/10.1053/j.jepm.2011.11.008

12. Musser JB, Fontana JL, Mongan PD (1999) The Anesthetic and Physiologic Effects of an Intravenous Administration of a Halothane Lipid Emulsion (5\% vol/vol). Anesth Analg 88:671-675. https://doi.org/10.1097/00000539-199903000-00038

13. Natalini CC, Da Silva Serpa PB, Cavalcanti RL et al (2016) General anesthesia with an injectable $8 \%$ v/v sevoflurane lipid emulsion administered intravenously to dogs. Vet Anaesth Analg 43:271-280. https://doi.org/10.1111/vaa.12317

14. Natalini CC, Krahn CL, Serpa PBS et al (2017) Intravenous $15 \%$ isoflurane lipid nanoemulsion for general anesthesia in dogs. Vet Anaesth Analg 44:219-227. 
https://doi.org/10.1016/j.vaa.2016.02.004

15. Mundi MS, Salonen BR, Bonnes SL, Hurt RT (2017) Parenteral Nutrition-Lipid Emulsions and Potential Complications. Pract Gastroenterol 41:32-37

16. Qin Z, Lv E, Zhan L et al (2014) Intravenous pretreatment with emulsified isoflurane preconditioning protects kidneys against ischemia / reperfusion injury in rats. BMC Anesth 14:1-8. https://doi.org/10.1186/1471-2253-14-28

17. Silva A, Campos S, Monteiro J et al (2011) Performance of Anesthetic Depth Indexes in Rabbits under Propofol Anesthesia: prediction probabilities and concentration-effect relations. Anesth 115:303-314. https://doi.org/10.1097/ALN.0b013e318222ac02

18. Watanabe H, Kamagata C, Tsuboko Y et al (2012) Volatile and Intravenous Anesthesia Alter Rat Liver Proteins: Proteomic Time Course Analysis of Rat Liver Proteins. The Open Proteomics J 5:8-16. https://doi.org/10.2174/1875039701205010008

19. Yan L, Jiang X, Tai W al (2012) Emulsified isoflurane induces postconditioning against myocardial infarction via JAK-STAT pathway. J Surg Res 178:578-585. https://doi.org/10.1016/j.jss.2012.06.007

20. Yang $X$, Zhang W, Liu J et al (2013) Pharmacokinetics of intravenous emulsified isoflurane in beagle dogs. Br J Anaesth 110:128-136. https://doi.org/10.1093/bja/aes311

21. Yang XL, Ma HX, Yang Z. Bin Liu AJ et al (2006) Comparison of minimum alveolar concentration between intravenous isoflurane lipid emulsion and inhaled isoflurane in dogs. Anesth 104:482-487. https://doi.org/10.1097/00000542-200603000-00015

22. Zhao J, Yuan Q, Cai W et al (2017) Formulation, Optimization, Characterization, and Pharmacokinetics of Progesterone Intravenous Lipid Emulsion for Traumatic Brain Injury Therapy. AAPS PharmSciTech 18:1475-1487. https://doi.org/10.1208/s12249-016-0637-5

23. Zhou J, Luo N, Liang X et al (2006) The Efficacy and Safety of Intravenous Emulsified Isoflurane in Rats. Anesth Analg 102:129-121. https://doi.org/10.1213/01.ane.0000189612.24147.07

\section{Tables}

Table 1. General considerations in all three treatments

\section{General consideration}

\begin{tabular}{ll}
\hline Weight $(\mathrm{g})$ & $318 \pm 13.8$ \\
\hline stabilization time (minute) & $10 \pm 1.8$ \\
\hline the volume of intranasal isoflurane $(\mathrm{ml})$ & $0.3 \pm 0.1$ \\
\hline room temperature $\left(\mathrm{C}^{\circ}\right)$ & $23 \pm 3$
\end{tabular}

Table 2. Physiological variables (mean \pm standard deviation) measured at 10 minute intervals for 30 minute during administration of inhaled isoflurane with ILE $30 \%$ and intravenous emulsified isoflurane 
Variables Treatment Anesthesia Intervals (minute)

\begin{tabular}{|c|c|c|c|c|c|}
\hline & & 0 & 10 & 20 & 30 \\
\hline \multirow[t]{3}{*}{${ }^{\star *} \mathrm{SpO}_{2} \%$} & Treatment I & $96 \pm 1.79$ & $96 \pm 0.41$ & $97 \pm 0.75$ & $96 \pm 1.72$ \\
\hline & Treatment II & $97 \pm 0.63$ & $98 \pm 0.84$ & $98 \pm 0.52$ & $96 \pm 1.17$ \\
\hline & Treatment III & $96 \pm 0.63$ & $99 \pm 0.9$ & $99 \pm 1.17$ & $96 \pm 1.17$ \\
\hline \multirow[t]{3}{*}{${ }^{* *} \mathrm{HR}$ (beats minute ${ }^{-1}$ ) } & Treatment I & $208 \pm 51.93$ & $163 \pm 41.3$ & $133 \pm 31.93$ & $215 \pm 41.08$ \\
\hline & Treatment II & $228 \pm 60.77$ & $150 \pm 13.07$ & $140 \pm 31.07$ & $214 \pm 44.71$ \\
\hline & Treatment III & $223 \pm 27.08$ & $131 \pm 53.88$ & $126 \pm 50.2$ & $162 \pm 61.15$ \\
\hline \multirow[t]{3}{*}{${ }^{\star \star} f_{R}\left(\right.$ beats minute $\left.{ }^{-1}\right)$} & Treatment I & $28 \pm 2.24$ & $23 \pm 3.69$ & $18 \pm 4.55$ & $29 \pm 1.25$ \\
\hline & Treatment II & $30 \pm 1.21$ & $13 \pm 1.19$ & $12 \pm 2.83$ & $32 \pm 0.4$ \\
\hline & Treatment III & $35 \pm 0.4$ & $14 \pm 2.54$ & $13 \pm 1.04$ & $27 \pm 1.39$ \\
\hline \multirow[t]{3}{*}{${ }^{* *} \mathrm{~T}\left(\mathrm{C}^{\circ}\right)$} & Treatment I & $42 \pm 0.8$ & $41 \pm 0.6$ & $39 \pm 1.1$ & $39 \pm 0.3$ \\
\hline & Treatment II & $41 \pm 0.5$ & $40 \pm 0.7$ & $40 \pm 0.8$ & $38 \pm 0.9$ \\
\hline & Treatment III & $41 \pm 0.7$ & $39 \pm 0.8$ & $38 \pm 0.7$ & $38 \pm 0.9$ \\
\hline
\end{tabular}

${ }^{* *} \mathrm{SpO}_{2}$ (peripheral hemoglobin oxygen saturation), $\mathrm{HR}$ (heart rate), $\mathrm{f}_{\mathrm{R}}$ (respiratory rate), $\mathrm{T}$ (temperature)

Table 3. Time-related parameters of anesthesia in pigeons

\begin{tabular}{lllllll} 
Treatment & $\begin{array}{l}\text { Dropping } \\
\text { of Head }\end{array}$ & $\begin{array}{l}\text { Lifting of } \\
\text { Head }\end{array}$ & $\begin{array}{l}\text { Immobilization } \\
\text { Time }\end{array}$ & $\begin{array}{l}\text { Duration of } \\
\text { Anesthesia }\end{array}$ & $\begin{array}{l}\text { Induction } \\
\text { Time }\end{array}$ & $\begin{array}{l}\text { Emergence } \\
\text { Time }\end{array}$ \\
$\begin{array}{l}\text { Treatment } \\
\text { I }\end{array}$ & $3 \pm 0.26$ & $34.5 \pm 3.15$ & $31.5 \pm 3.51$ & $14.17 \pm 1.64$ & $10.5 \pm 2.02$ & $7.3 \pm 1.03$ \\
\hline $\begin{array}{l}\text { Treatment } \\
\text { II }\end{array}$ & $3 \pm 0.89$ & $43.5 \pm 4.14^{\star}$ & $40.5 \pm 4.42$ & $17 \pm 3$ & $6.3 \pm 2.97^{\star}$ & $19 \pm 2^{*}$ \\
\hline $\begin{array}{l}\text { Treatment } \\
\text { III }\end{array}$ & $3.67 \pm 0.82$ & $40 \pm 4.09$ & $36.3 \pm 3.11$ & $18.17 \pm 2$ & $4 \pm 3.14^{*}$ & $13.83 \pm 3^{*}$
\end{tabular}

Time courses are showed in minutes and indicated as mean \pm SD

*Significantly different from Treatment I $(p<0.05)$

\section{Figures}




\section{Anesthesia Score}

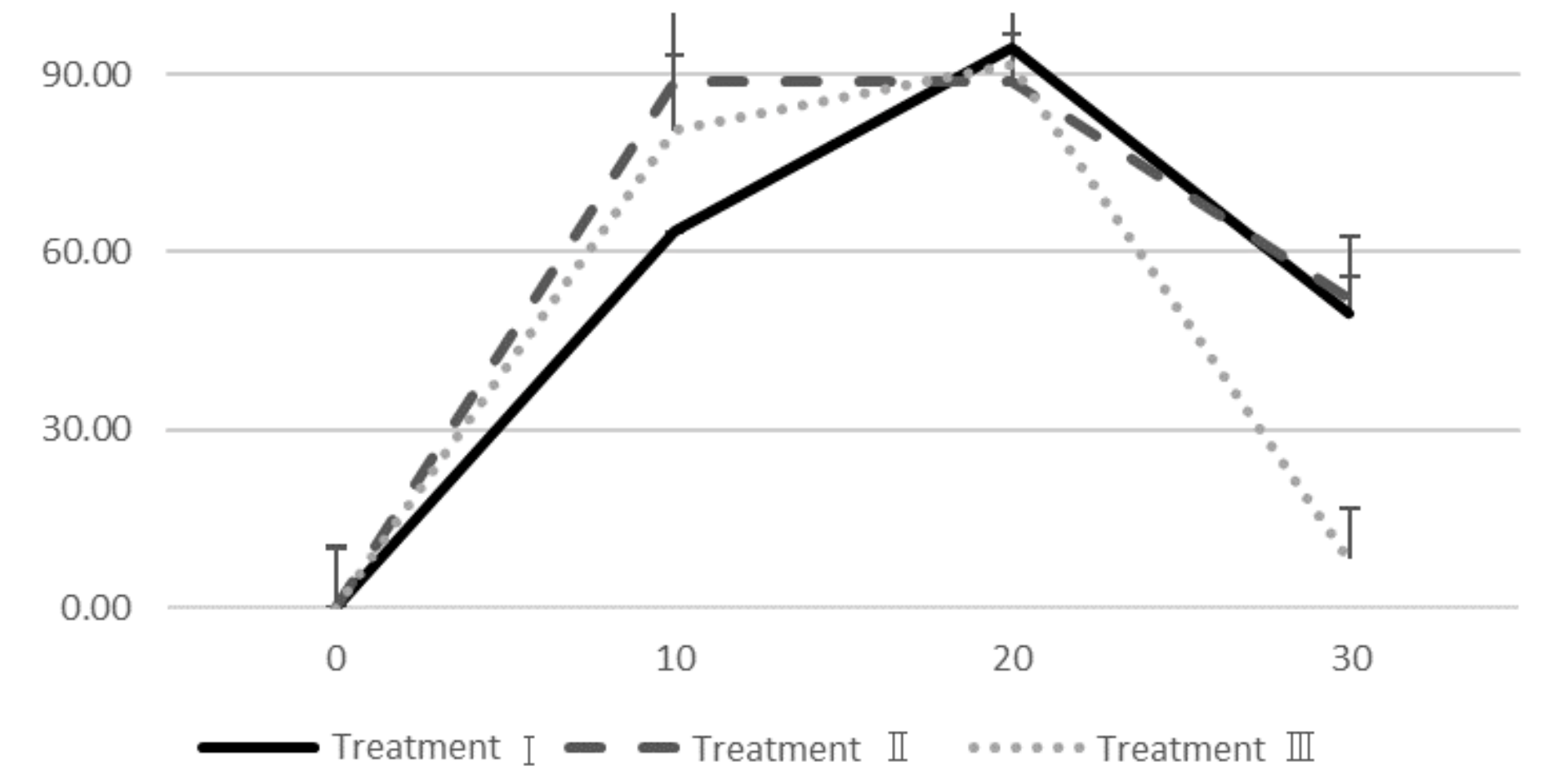

\section{Figure 1}

Anesthesia score in ten minute intervals in all three treatments

\begin{tabular}{|c|c|c|c|c|}
\hline \multirow[t]{2}{*}{$\begin{array}{l}\text { Start of Administration } \\
\text { (Zero Time) }\end{array}$} & \multicolumn{2}{|c|}{$\begin{array}{l}\text { Withdrawal of administration } \\
(20 \text { minutes after start) }\end{array}$} & & \\
\hline & Infusion & \multicolumn{3}{|c|}{ Pigeon Monitoring } \\
\hline 70 & 10 & 30 & 40 & 50 \\
\hline
\end{tabular}

Preparation \&

Stabilization $(10.1 \pm 1.8)$

Figure 2

Experimental design in this study, all data were recorded in 10 minute intervals. 


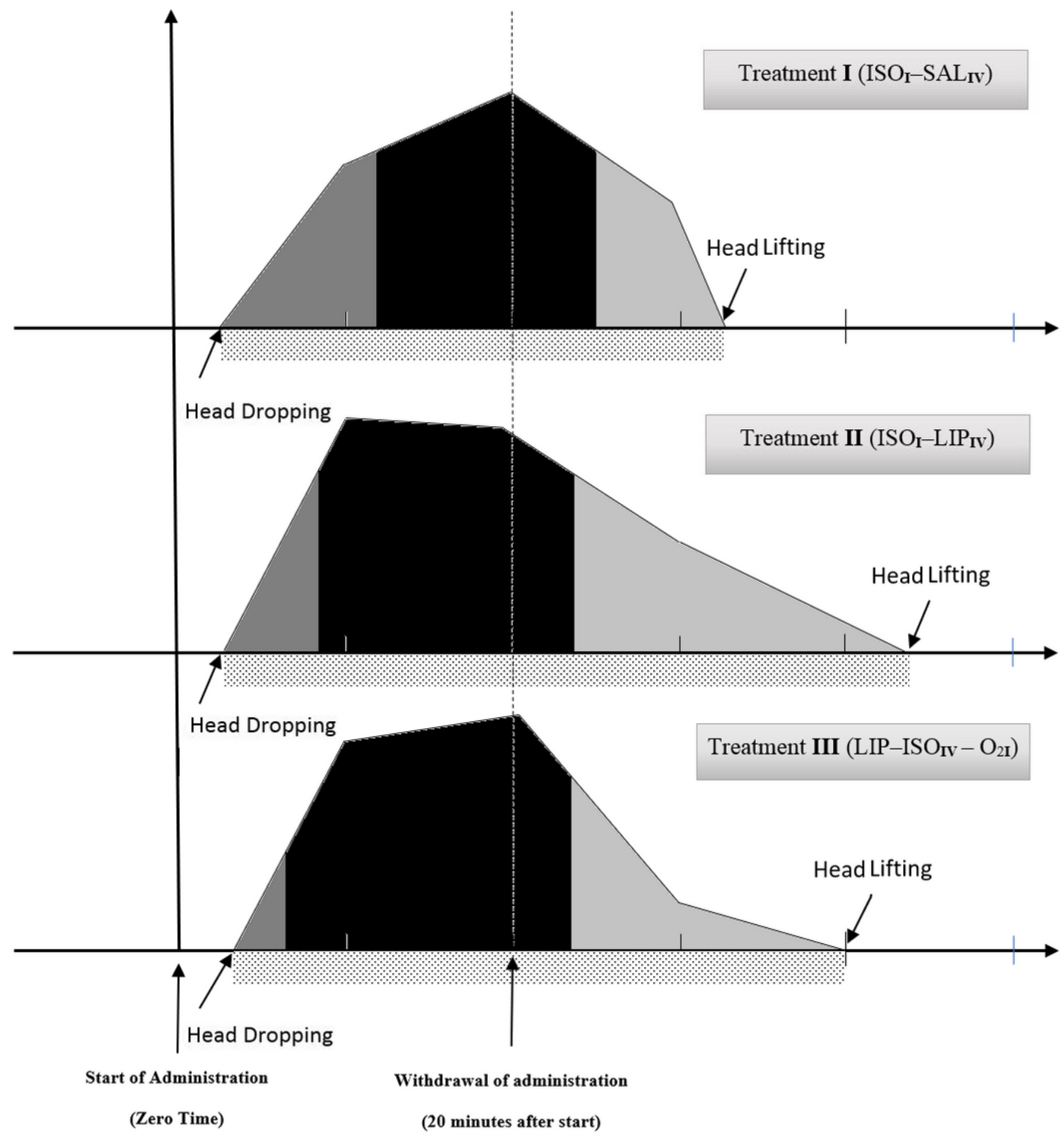

Immobilization Time $(\operatorname{ImT})$ ? Induction Time (InT) $\square$ Duration of Anesthesia (DA) $\square$ Emergence Time (ET)

\section{Figure 3}

Gradient graph shows two parameters, stages of anesthesia and time-related 